\title{
Increasing Incidence of Hepatitis A in Korean Adults
}

\author{
Yoon Jun Kim Hyo-Suk Lee \\ Department of Internal Medicine and Liver Research Institute, Seoul National University College of Medicine, \\ Seoul, Korea
}

\section{Key Words}

Epidemiology · Hepatitis A, acute - Hepatitis A virus •

Korea $\cdot$ Vaccination

\begin{abstract}
Hepatitis A infection is caused by the hepatitis A virus (HAV), which is transmitted through the fecal-oral route. Lifelong protective antibodies are present after infection. The number of cases of adult hepatitis A has progressively been increasing during the last several decades in Korea. In addition, the pattern of age-specific seroprevalence of anti-HAV has changed with economic growth. The prevalence of anti-HAV in the 10-50-year age range has declined rapidly during the last 3 decades. As a result, this age group has a high risk for $\mathrm{HAV}$ infection and clinically overt hepatitis $A$ is increasing in adolescents and adults. It is well established that the severity of the disease is related to the age of the patients. The development of more cases of adult hepatitis A with severe presentation is expected in the near future. The clinical features and the epidemiological shift of HAV underscore the importance in Korea, as well as in other countries with similar issues, of childhood vaccination and consideration of catchup vaccination for adolescents and adults as well as of targeted vaccination for individuals at increased risk for infection or its complications. There is a need to extensively evaluate the nationwide epidemiology of HAV infection, make cost-benefit analyses of HAV vaccination, and establish guidelines for HAV vaccination.
\end{abstract}

Copyright $\odot 2010$ S. Karger AG, Basel (c) 2010 S. Karger AG, Basel

0300-5526/10/0531-0010\$26.00/0

Fax +41613061234

E-Mail karger@karger.ch

www.karger.com
Accessible online at:

www.karger.com/int

\section{Introduction}

Viral hepatitis is a major public health problem throughout the world. The hepatitis A virus (HAV) is an unenveloped, single-stranded, positive-sense RNA virion [1] belonging to the family Picornaviridae, genus Hepatovirus [2]; it is characterized by resistance to heat and acid. The particles were initially visualized in stools obtained from hepatitis A patients in 1973 [3]. HAV infection usually occurs through fecal-oral transmission, either by direct contact with an infected person or by ingestion of food or water contaminated with HAV [4]. Hepatitis A has an uneven worldwide distribution among different geographical regions and population groups. In many regions, the epidemiology of hepatitis A has been changing due to improved sanitation and living standards.

HAV infection in early childhood is usually asymptomatic or only mildly symptomatic. The relative frequency of symptomatic hepatitis and asymptomatic infection has been reasonably well characterized and is agedependent [5]. Regardless of the symptoms, seroconversion occurs after infection and convalescent individuals develop permanent immunity [6]. Improved hygiene and sanitary conditions have significantly reduced the incidence of hepatitis A infection. However, paradoxically, symptomatic HAV infections have been increasing in rapidly developing countries. 
With improvement in socioeconomic conditions in Korea, early childhood exposure to the virus has decreased. Hence, there has been a gradual shift in the age of infection from early childhood to adulthood. Concomitantly, there has been an increase in symptomatic cases and in severe clinical outcomes including liver failure. In this review, we discuss the recent increase of symptomatic HAV infection, the shifting of seroprevalence of HAV in Korea, and the strategies for HAV vaccination in Korea and other countries experiencing a similar epidemiological shift in HAV.

\section{Increasing Incidence of Symptomatic HAV Infection in Korea}

The rapid improvement of living standards and sanitation due to economic growth has been associated with an equally rapid decrease in age-specific anti-HAV prevalence, whilst paradoxically at the same time the incidence of clinical disease has increased. In highly endemic areas, people become infected with HAV during early childhood and acquire anti-HAV antibodies before 10 years of age. As infections in early childhood are either asymptomatic or mild, hepatitis A is not a clinical problem and the virus is identified only by serological studies or the occurrence of infection among visitors. In intermediate or transition areas, HAV circulation has been reduced by improved hygiene conditions and socioeconomic status. Those who become infected in intermediate or transition areas are older than those in highly endemic areas, and the incidence of symptomatic hepatitis $\mathrm{A}$ is higher in adolescents and adults. Frequent outbreaks of hepatitis A are recognized as a serious public health problem [7]. In low endemic areas, the rare occurrence results in populations that do not have immunity. Susceptible adults who are exposed to HAV infection and symptomatic hepatitis A are mostly high-risk groups such as child-care providers, family members of patients, travelers to endemic areas, drug abusers and men who have sex with men.

Until 30 years ago, most adults in Korea had immunity to HAV. However, the number of adult cases of acute hepatitis A has progressively increased during the last 2 or 3 decades, reflecting the changing epidemiology of HAV due to the rapid improvement in socioeconomic status [8]. The Korea Centers for Disease Control and Prevention reported that the number of symptomatic HAV infections has been increasing exponentially since 2006 (fig. 1). This changing pattern of hepatitis A epide-

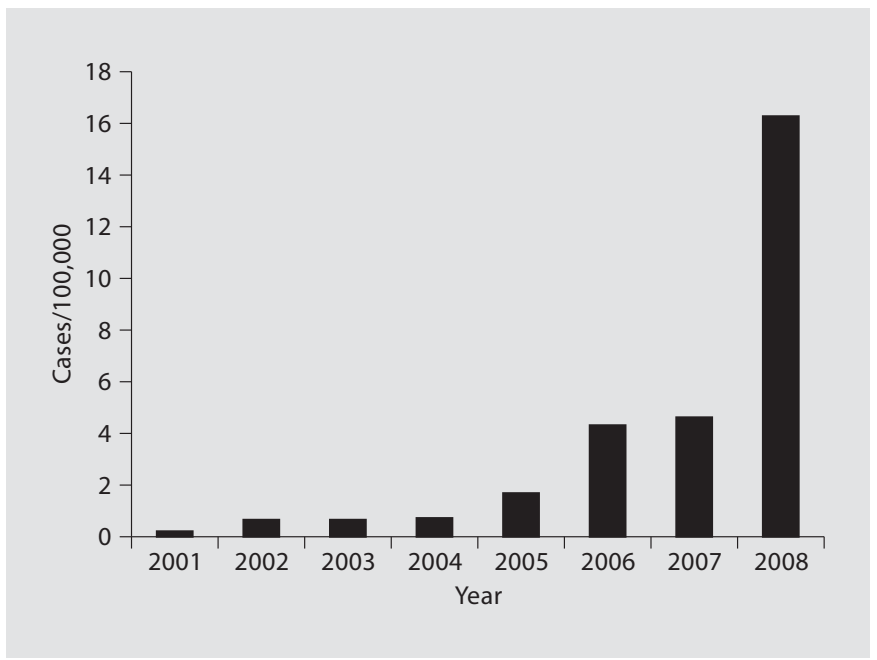

Fig. 1. Reported incidence of hepatitis A in Korea, 2001-2008. Data from the Korea Centers for Disease Control and Prevention.

miology has been observed in many Asian countries, shifting from hyperendemicity to low endemicity, especially in recently developed and affluent metropolitan communities [8-11].

\section{Hepatitis A Epidemiological Shift and Regional Heterogeneity in Seroprevalence in Korea}

The improved socioeconomic status, urbanization, ethnic origin and access to clean water and sanitation have changed the epidemiology of hepatitis A. The distribution of anti-HAV seroprevalence by age might reflect the current hepatitis A status in various regions and countries $[12,13]$. The peak age of seroprevalence is shifting from the first decade oflife to the second, third, fourth and even fifth decades. This shift in age of acquiring the infection from childhood to older age groups is referred to as an epidemiological shift. In the past, hepatitis A was not a major problem among adults in Korea, since almost all Koreans acquired anti-HAV antibodies through natural infection during childhood, when the disease is usually asymptomatic. During 1982, the anti-HAV seropositivity in Korean children under 10 years of age, was about $45 \%$, whereas in adults over 20 years of age it was more than $90 \%$. With improved economic status and sanitation, a seroepidemiology survey from 1982 to 2006 showed that the age-specific seroprevalence of HAV antibody decreased dramatically among all age groups 


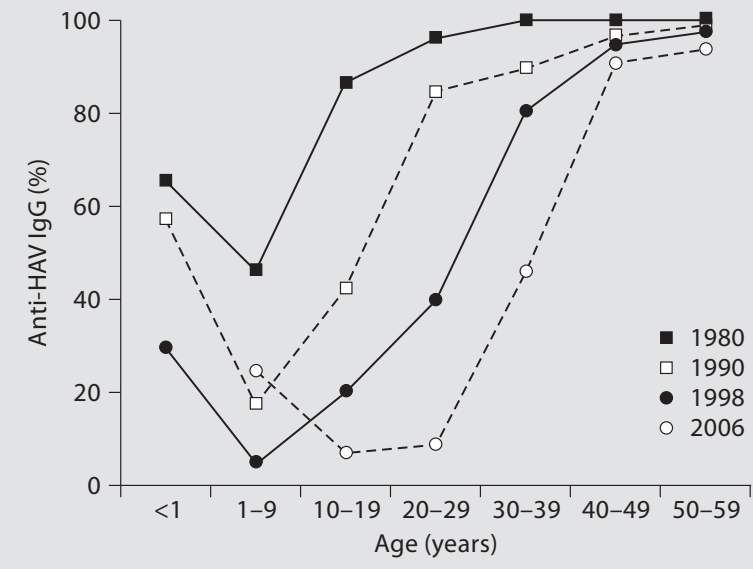

Fig. 2. Epidemiological shift of the seroprevalence of hepatitis A in Korea. This figure shows the change of estimated seroprevalence of hepatitis A in Korea from 1980 to 2006. Figure from Lee et al. [15].

(fig. 2) $[14,15]$. Consequently, several outbreaks of hepatitis A have occurred in Korean young adults during the past 2 or 3 decades. HAV outbreaks represent the transition from an endemic HAV transmission pattern to an epidemic pattern.

The marked reduction in virus transmission in most developed countries occurred several decades ago due to improvement in living standards, better sanitation and environmental status in addition to higher incomes. The same trend has been observed in several developing countries with increasing economic prosperity during the 1990s, e.g. Spain, Greece, Israel, Singapore and other countries [16-19]. Therefore, it is highly likely that this increasing trend of hepatitis A cases in young adults is a reflection of the recent shift of HAV epidemiology, suggesting that increasing numbers of adults do not have protective antibodies against HAV [15].

Furthermore, an evolving epidemiological shift is occurring in certain areas, and among certain groups of populations in Korea. A recent study showed that the seroprevalence was higher in residents of the provinces when compared to those of Seoul in the age group below 40 years, and that the seroprevalence in the less affluent areas was higher than in the more affluent areas, even in Seoul [20]. Such findings have also been observed in Saudi Arabia, China and Latin America [10, 21, 22]. Therefore, heterogeneous populations are likely to co-exist within the same geographic areas, with diverse economic and social classes in Korea. The rapidly evolving epidemiological shift and regional heterogeneity might be the underlying cause of a rapid increase of symptomatic HAV infection.

\section{Effect of Vaccination}

The social and economic burden of the morbidity and mortality associated with hepatitis A has led to the development of several vaccines. The hepatitis A vaccine is an inactivated preparation of cell culture-adapted HAV that has been used in many parts of the world. Since 1997, hepatitis A vaccines have been available in Korea. Hepatitis A vaccines are highly effective in preventing hepatitis A in individuals and in reducing community outbreaks $[23,24]$. Epidemiological studies and economic evaluations of hepatitis A vaccination reported elsewhere in various risk groups, such as adolescents in Hong Kong [9], health-care workers [25], frequent travelers [26] or military personnel [27], have suggested that vaccination is indeed cost-effective. However, recommendations for the use of hepatitis A vaccine vary considerably among different countries. In Israel, a universal toddlers-only immunization program without catch-up vaccination has demonstrated high efficacy and excellent herd protection, which has led to the questioning of the need for a catch-up vaccination program [24]. In 2005, encouraged by the success of targeted vaccination, the American Advisory Committee on Immunization Practices recommended universal childhood HAV vaccination in all children between the ages of 12 and 23 months in the United States. That decision was based on the favorable results of a cost-effectiveness analysis of routine childhood vaccination [28]. A study from Chile also supports the cost-effectiveness of universal childhood hepatitis A vaccination [29].

\section{Potential Strategies for HAV Vaccination in Korea}

Strategies to immunize and protect against HAV infection can be broadly categorized into 3 groups. The first option is to have an immunization strategy that focuses on the individuals/groups at high risk. The target should be individuals at increased risk for infection or its complications. The second intervention type is designed to avoid outbreaks of HAV among susceptible populations. In Korea, the most vulnerable population for symptom- 
atic HAV infection is the 10-50-year age group. The third strategy is to vaccinate all children regardless of their individual risk status for acquiring HAV infection, with the ultimate aim of eliminating the infection from the community. All of these options are likely to prevent/minimize the risk of HAV disease in susceptible adults.

When the anti-HAV seroprevalence rate is high, selective vaccination according to the anti-HAV serostatus is more cost-effective than a universal vaccination program. In an analysis of the cost-effectiveness of different vaccination strategies, Saab et al. [30] found that screening for anti-HAV was less costly than vaccination, without checking the HAV serology, when the anti-HAV prevalence exceeded $35 \%$ and the cost of serological testing was less than USD 25. In patients with chronic liver disease, the results of a study performed in Korea suggested selective vaccination programs for 31- to 40 -yearold patients (anti-HAV rate of $64-85 \%$ ) and universal vaccination for patients younger than 31 years of age (anti-HAV rate of $0-34 \%$ ) [31]. In addition to the seroprevalence data, the cost of serological testing, the cost of vaccination, and the likelihood of the occurrence of a clinically significant HAV infection should be determined to facilitate the identification of the most efficient vaccination strategy.

In accordance with the recent increase in the frequency of HAV vaccinations, the HAV seroprevalence of a Korean pediatric population younger than 10 years of age has been reported to be about $50 \%$, probably as a result of private immunization [17]. Therefore, an active campaign for childhood vaccination and government-sponsored nationwide routine vaccination of children against HAV should be considered. However, only about $10 \%$ of the age group between 10 and 30 years have positive antiHAV (IgG), indicating a missing age group with regard to HAV vaccination [15]. In addition to routine childhood vaccination, catch-up vaccination, which is directed at the age group of 10-50 years, should be considered. This would rapidly reduce the disease burden of hepatitis A in Korea and other countries that are experiencing an epidemiologic shift similar to the one in Korea; however, further discussion about this issue is needed. Pre-vaccination serological testing can certainly reduce the cost, especially in the 30-50-year age group, while it might not necessarily in the 10-30-year age group [15]. Furthermore, adoption of a vaccination program for high-risk groups and for people with chronic liver disease should also be considered [31,32]. Further nationwide largescale studies, including the active evaluation of the clinical significance of acute HAV infection and cost-benefit analyses of different vaccination strategies in different age groups, will provide important information needed for designing an optimal vaccination strategy.

\section{Conclusions}

Heterogeneous populations of susceptible and exposed individuals may co-exist in rapidly developing societies. Thereafter, outbreaks of HAV infection will remain a threat in such areas. HAV seroepidemiology in Korea is rapidly changing and a growing number of adolescents and adults are susceptible to HAV infection. Furthermore, heterogeneous populations are likely to co-exist within very close geographic areas. An active campaign for universal childhood HAV vaccination should be continued and catch-up vaccination, which is directed at 10-50-year-olds, should be considered in Korea and other countries experiencing similar issues. Additionally, conventional high-risk groups and more vulnerable groups at risk for developing fulminant hepatitis (such as travelers to highly endemic areas, patients medicated with clotting factors and patients with chronic liver disease) should be vaccinated. To provide evidence-based recommendations for HAV vaccination, an urgent nationwide survey of HAV seroepidemiology as well as a regional surveys and studies of the cost-effectiveness of vaccination of each vaccination strategy are needed.

\section{Acknowledgment}

This study was supported by a grant from the Seoul National University Hospital (No. 302009-0130).

\section{Disclosure Statement}

The authors declare that there is no conflict of interest regarding this study. 


\section{References}

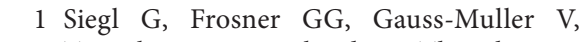
Tratschin JD, Deinhardt F: The physicochemical properties of infectious hepatitis a virions. J Gen Virol 1981;57:331-341.

$\checkmark 2$ Robertson BH, Jansen RW, Khanna B, Totsuka A, Nainan OV, Siegl G, Widell A, Margolis HS, Isomura S, Ito K, et al: Genetic relatedness of hepatitis $\mathrm{A}$ virus strains recovered from different geographical regions. J Gen Virol 1992;73:1365-1377.

\3 Feinstone SM, Kapikian AZ, Purceli RH: Hepatitis A: Detection by immune electron microscopy of a viruslike antigen associated with acute illness. Science 1973;182:10261028 .

$\checkmark 4$ Fiore AE: Hepatitis A transmitted by food. Clin Infect Dis 2004;38:705-715.

5 Hadler SC, Webster HM, Erben JJ, Swanson JE, Maynard JE: Hepatitis A in day-care centers: a community-wide assessment. N Engl J Med 1980;302:1222-1227.

6 Koff RS: Clinical manifestations and diagnosis of hepatitis A virus infection. Vaccine 1992;10(suppl 1):S15-S17.

$\checkmark 7$ Xu ZY, Li ZH, Wang JX, Xiao ZP, Dong DX: Ecology and prevention of a shellfish-associated hepatitis A epidemic in Shanghai, China. Vaccine 1992;10(suppl 1):S67-S68

$\checkmark 8$ Sohn YM, Rho HO, Park MS, Park JH, Choi BY, Ki M, Jang WI: The changing epidemiology of hepatitis A in children and the consideration of active immunization in Korea. Yonsei Med J 2000;41:34-39.

$\checkmark 9$ Lee A, Cheng F, Lau L, Lo A, Fabb WE: Changing hepatitis A epidemiology among Hong Kong Chinese adolescents: what are the implications? Public Health 1999;113: 185-188.

10 Barzaga BN: Hepatitis A shifting epidemiology in South-East Asia and China. Vaccine 2000;18(suppl 1):S61-S64.

-11 Wang SM, Liu CC, Huang YS, Yang YJ, Lei HY: Change in hepatitis A virus seroepidemiology in southern Taiwan: a large percentage of the population lack protective antibody. J Med Virol 2001;64:104-108.
12 Gust ID: Epidemiological patterns of hepatitis A in different parts of the world. Vaccine 1992;10(suppl 1):S56-S58.

13 Jacobsen KH, Koopman JS: The effects of socioeconomic development on worldwide hepatitis A virus seroprevalence patterns. Int J Epidemiol 2005;34:600-609.

14 Sohn YM, Lee JS, Park JH, Poerschke G, Eves $\mathrm{K}$, Gress J, Kuter B: Immunizing children to protect against the increasing risk of hepatitis A in adolescents and young adults in South Korea. Southeast Asian J Trop Med Public Health 2004;35:954-958.

15 Lee D, Cho YA, Park Y, Hwang JH, Kim JW, Kim NY, Lee DH, Lee W, Jeong SH: Hepatitis A in Korea: epidemiological shift and call for vaccine strategy. Intervirology 2008;51:7074.

16 Amela C, Pachon I, Bueno R, de Miguel C, Martinez-Navarro F: Trends in hepatitis A virus infection with reference to the process of urbanization in the greater Madrid area (Spain). Eur J Epidemiol 1995;11:569-573.

17 Kremastinou J, Kalapothaki V, Trichopoulos $\mathrm{D}$ : The changing epidemiologic pattern of hepatitis A infection in urban Greece. Am J Epidemiol 1984;120:703-706.

18 Schwartz E, Raveh D: The prevalence of hepatitis $\mathrm{A}$ antibodies among Israeli travellers and the economic feasibility of screening before vaccination. Int J Epidemiol 1998;27: $118-120$.

19 Shapiro CN, Margolis HS: Worldwide epidemiology of hepatitis A virus infection. J Hepatol 1993;18(suppl 2):S11-S14.

20 Song YB, Lee JH, Choi MS, Koh KC, Paik SW, Yoo BC, Choi YH, Sohn HJ, Lee KH, Rhee JC: The age-specific seroprevalence of hepatitis A virus antibody in Korea (article in Korean). Korean J Hepatol 2007;13:27-33.

21 Tufenkeji H: Hepatitis A shifting epidemiology in the Middle East and Africa. Vaccine 2000;18(suppl 1):S65-S67.

22 Tanaka J: Hepatitis A shifting epidemiology in Latin America. Vaccine 2000;18(suppl 1): S57-S60.
23 Jenson $\mathrm{HB}$ : The changing picture of hepatitis A in the United States. Curr Opin Pediatr 2004;16:89-93.

24 Dagan R, Leventhal A, Anis E, Slater P, Ashur Y, Shouval D: Incidence of hepatitis A in Israel following universal immunization of toddlers. JAMA 2005;294:202-210.

25 Smith S, Weber S, Wiblin T, Nettleman M: Cost-effectiveness of hepatitis A vaccination in healthcare workers. Infect Control Hosp Epidemiol 1997;18:688-691.

26 Fenn P, McGuire A, Gray A: An economic evaluation of vaccination against hepatitis A for frequent travellers. J Infect 1998;36:1722.

27 Buma AH, Beutels P, van Damme P, Tormans G, van Doorslaer E, Leentvaar-Kuijpers A: An economic evaluation of hepatitis A vaccination in Dutch military personnel. Mil Med 1998;163:564-567.

28 Rein DB, Hicks KA, Wirth KE, Billah K, Finelli L, Fiore AE, Hoerger TJ, Bell BP, Armstrong GL: Cost-effectiveness of routine childhood vaccination for hepatitis $\mathrm{A}$ in the United States. Pediatrics 2007;119:e12-e21.

29 Valenzuela MT, Jacobs RJ, Arteaga O, Navarrete MS, Meyerhoff AS, Innis BL: Costeffectiveness of universal childhood hepatitis A vaccination in Chile. Vaccine 2005;23: 4110-4119.

30 Saab S, Martin P, Yee HF Jr: A simple costdecision analysis model comparing two strategies for hepatitis A vaccination. Am J Med 2000;109:241-244.

>31 Song HJ, Kim TH, Song JH, Oh HJ, Ryu KH, Yeom HJ, Kim SE, Jung HK, Shim KN, Jung SA, Yoo K, Moon IH, Chung KW: Emerging need for vaccination against hepatitis $\mathrm{A}$ virus in patients with chronic liver disease in Korea. J Korean Med Sci 2007;22:218-222.

32 Kang CI, Choi CM, Park TS, Lee DJ, Oh MD, Choe KW: Incidence and seroprevalence of hepatitis A virus infections among young Korean soldiers. J Korean Med Sci 2007;22: 546-548. 